\title{
: LER E ESCREVER: O QUE A GRAMÁTICA TEM A VER : COM ISSO?
}

\section{READING AND WRITING: WHAT HAS GRAMMAR TO DO WITH THIS?}

Ana Lima (UFPE) ${ }^{1}$

\section{RESUMO}

Ainda hoje é bastante comum a prática escolar de se tratar isoladamente a leitura, a escrita e a gramática, como se essas fossem instâncias que pouco dialogam. Nessa perspectiva, a escola tem conferido à leitura e à escrita um tratamento cada vez mais distanciado do que de fato são essas atividades, socialmente. Com a priorização dos conhecimentos gramaticais, as aulas de leitura e de escrita têmse transformado em pretextos para o estudo de questões normativas. Pretendemos defender, neste trabalho, que, na contramão do que se tem feito na escola, o conhecimento gramatical deve atuar como suporte para as atividades de leitura e de escrita, e não o inverso. Entretanto, para que esse movimento se realize de maneira eficaz, é preciso, antes de tudo, que o professor adote uma concepção de leitura e de escrita mais afinada com as demandas da sociedade atual. Assim, na esteira de Freire (1984), Kleiman (1989), Soares (1998), Dell'Isola (1991), dentre outros autores, a leitura não pode mais ser concebida como um simples mecanismo de decodificação e ativação dos conhecimentos; nem a escrita como a mera junção de frases que se articulam. Antes, leitura e escrita devem ser compreendidas como processos de negociação de sentidos, como práticas enunciativas, marcadas pela interação autor-texto-leitor. São processos extremamente complexos, que abrangem dimensões muito variadas e operações interdependentes e concomitantes, seja do ponto de vista estritamente linguístico e cognitivo, seja do ponto de vista semiótico e social. Mas, para a efetivação dessas atividades tão complexas, que papel tem a 'gramática'? Como o professor pode integrar gramática, leitura e escrita? São essas as principais questões sobre as quais pretendemos refletir.

PALAVRAS-CHAVE: Leitura; Escrita; Gramática; Ensino.

1 Doutora em Linguística e Língua Portuguesa pela Universidade Estadual Paulista Júlio de Mesquita Filho. Email: jalaraujolima@uol.com.br 


\section{ABSTRACT}

It is still very common for schools to treat the skills of reading, writing and grammar separately, as if these skills do not interact. This approach does not coincide with how these skills are, in fact, used in the real world of social interaction. Giving priority to grammar knowledge, teachers transform reading and writing classes into exercises in dealing with normative aspects of the language. In this work, our aim is to defend a view that is different from what is traditionally practiced in schools, namely that grammatical knowledge should support reading and writing activities, and not the opposite. However, to accomplish this shift in practice, it is first necessary for teachers to adopt a different view of reading and writing, a view that corresponds to contemporary social demands. Thus, following Freire (1984), Kleiman (1989), Soares (1998), Dell'Isola (1991), among other researchers, reading cannot be conceived of as only a simple decoding mechanism, or as a mechanism of knowledge activation. Furthermore, writing cannot be seen as mere articulation of phrases that are linked together. Instead, reading and writing should be understood as processes of meaning negotiation-as interaction practice-in which author, text and reader jointly participate. These processes and practices are extremely complex, and deal with very distinct domains as well as interdependent and parallel actions, not only linguistic, but also cognitive, semiotic and social dimensions. Within such a complex activity, what is the role of grammar? How can teachers integrate grammar, reading and writing? These are the main questions which we intend to address.

KEYWORDS: Reading; Writing; Grammar; Teaching.

\section{CONSIDERAÇÕES INICIAIS}

Uma das práticas escolares mais recorrentes é a de tratarde forma isolada a leitura, a escrita e a gramática, como se não houvesse diálogo entre esses eixos de ensino. A fragmentação da disciplina 'português' em aulas de 'gramática' - em que se apresentam algumas regras do sistema linguístico e se trabalha alguma nomenclatura - e aulas de 'redação' ou de 'produção de textos' - em que se leem e se escrevem textos de 
variados gêneros -, com horários e professores diferentes, é tão comum : nos currículos das escolas que nos acostumamos a percebê-la como 'normal'. E, no tripé gramática-leitura-escrita, ainda prevalece, nas aulas de português, o trabalho com a 'gramática', o que se evidencia pelo tempo bem maior dedicado a esse conteúdo na grade curricular das escolas.Ao privilegiar atividades que objetivam o domínio de questões gramaticais, a escola tem conferido à leitura e à escrita um tratamento cada vez mais distanciado da relevância que essas duas práticas têm, de fato, na sociedade em que vivemos. Em alguns casos, a priorização de atividades que visam à apreensão dos conhecimentos gramaticais tem sido tão acentuada que até os momentos reservados para as aulas de leitura e de escrita são também ocupados com o estudo de questões normativas, com a diferença, apenas, de que, nesses momentos, o estudo gramatical é intermediado pelo texto.

Nesse contexto, pretendemos defender, no presente trabalho, que, na contramão do que se tem feito na escola, o conhecimento gramatical deve ser trabalhado como suporte (ou com "função instrumental", nas palavras de SILVA, s/d) para as atividades de leitura e de escrita, e não o inverso. Sabemos, entretanto, que, para que esse movimento se realize de maneira eficaz, é preciso, antes de tudo, que o professor adote uma concepção de leitura e de escrita mais afinada com as demandas da sociedade atual.

Assim, na esteira de vários estudiosos, a exemplo de Kleiman (1995), Soares (2003; 2006), Dell'Isola (1991), dentre outros, ratificamos a ideia de que a leitura não pode mais ser concebida apenas como um mecanismo de decodificação e ativação dos conhecimentos, apesar de reconhecermos que essas são etapas importantes do processo de leitura (RODRIGUES, 2007); nem a escrita como a mera junção de frases que se articulam (MARCUSCHI, 2008; ANTUNES, 2009). Ao invés disso, leitura e escrita devem ser compreendidas como processos de negociação de sentidos, como práticas enunciativas, marcadas pela interação autor-texto-leitor. São atividades extremamente complexas, que abrangem estratégias muito variadas e operações interdependentes e concomitantes, seja do ponto de vista estritamente linguístico e cognitivo, seja do ponto de vista semiótico e social.

Mas, para que essas atividades sejam realizadas de maneira eficaz, que papel tem a 'gramática'? Como o professor pode integrar gramática, 
leitura e escrita? São essas as principais questões sobre as quais pretendemos refletir. Para alcançar os objetivos pretendidos, primeiramente vamos discutir acerca das noções de leitura e de escrita; na sequência, vamos tratar da 'gramática', em sua relação com essas duas atividades.

\section{Sobre as noções de 'leitura' e 'escrita'}

Já há cerca de trinta anos ${ }^{2}$, especialistas das áreas da Linguagem e da Educação introduziram, nos estudos dessas áreas, a distinção entre as noções de "alfabetização" e "letramento". A primeira, pontual, refere-se à aquisição de um código (o alfabeto), que habilita o aprendiz a codificar em língua escrita e a decodificar o que está escrito. A segunda, que se estende ao longo de toda a nossa vida, refere-se ao envolvimento dos sujeitos nas práticas sociais de leitura e de escrita.

Essa distinção, fundamental para a prática docente, parece não ter sido ainda bem compreendida por muitos professores, incompreensão que pode estar na base de uma certa “banalização da leitura”, denunciada por Gomes (2003, p.82). De acordo com essa autora, a banalização da leitura transforma essa atividade em

um ato mecânico, ou seja, desprovido do verdadeiro sentido que uma leitura significativa deve ter: atribuir acepções, estabelecendo elos com o conhecimento de mundo. Muito mais do que um mero mecanismo de decodificação e ativação dos conhecimentos, a leitura deve ser um processo interativo e de compreensão do mundo.

A superação dessa "banalização da leitura" e a ampliação do significado de "ler" vêm ocorrendo, hoje, em ritmo acelerado. Mas a leitura vem sendo objeto de reflexão há muito tempo, reflexão que se intensificou a partir da disseminação do pensamento de Paulo Freire, para quem a leitura da palavra teria de ser precedida pela leitura do mundo.

2 Segundo Soares (2006), Mary Kato foi uma das primeiras autoras a utilizar o termo "letramento", em texto de 1986, enquanto Leda Tfouni, em obra de 1988, distingue "alfabetização" de "letramento". No texto "As muitas facetas da alfabetização" (SOARES, 2003),cuja primeira versão é de 1985, a própria Magda Soares diferencia o "processo de aquisição" do "processo de desenvolvimento"da língua oral e escrita (grifos da autora), contribuindo, assim, para lançar as bases da distinção entre as noções de "alfabetização" e "letramento". 
: Com base no pensamento de Freire, Rodrigues (2007, p.222) defende a : visão de que o mundo é, "metaforicamente, um enorme hipertexto que precisa ser decodificado, compreendido, interpretado para fazer sentido. Nossa existência precisa ser lida para ser significada.”.

No estágio atual dos estudos sobre as práticas de letramento, não cabe mais a concepção de leitura como um ato mecânico de decodificação do texto escrito, por meio do qual o aluno deve apenas articular de maneira correta os fonemas e pronunciar as frases em um ritmo adequado, marcando bem as pausas e a entonação exigidas pelos sinais de pontuação.

Longe disso, atualmente, "o desafio da leitura está na busca de significações que ultrapassam a superfície do texto"; na busca das "diversas possibilidades de contextualização com o real que um texto pode suscitar" (GOMES, 2003, p.84), para que o leitor proceda a reflexões que o levem a uma mudança de comportamento.

Em consonância com essa concepção, Ribeiro (2003, p.109) afirma que

a leitura é reconhecida como um processo que transcende ao próprio texto. A compreensão do texto que se pretende ideal implica a percepção das relações entre texto, contexto e intertexto. A leitura, nessa concepção, não está presa somente à palavra, mas a todo um mundo subjacente a ela, que vai sendo construído, antes mesmo de sua convenção.

Nessa mesma direção seguem as afirmações de Santos (2002, p.3), para quem

o ato de ler é concebido como um processo interativo entre autor e leitor, mediado pelo texto, envolvendo conhecimentos (de mundo, de língua) por parte do leitor, para que haja compreensão. Ou seja, a leitura não é um processo mecânico e o leitor não é um elemento passivo, como costumam concebê-los na escola. No processo de leitura, o leitor realiza um trabalho ativo de construção do significado. Ler, portanto, não é apenas extrair informações, é, antes de tudo, compreender e negociar sentidos. 
Assim, a atividade de leitura é considerada, nos dias atuais, a partir de, pelo menos,três dimensões: a da inter-relação autor-leitor, sujeitossóciohistoricamente situados que atuam dialogicamente na coconstrução dos sentidos do texto; a do próprio texto, evento que faz a intermediação entre os sujeitos que participam da dinâmica interacional; e a do contexto mais amplo em que a leitura se processa, aqui incluídos todos os aspectos intervenientes na produção e recepção do texto (aspectos sociais, culturais, históricos etc.).

Com essas bases, a leitura é compreendida, hoje, como um processo de coenunciação, visão da qual decorre a consideração de que o acesso ao material textual não se faz por meio de uma única estratégia, mas, antes, por meio de estratégias diversificadas. Santos (2002) defende que essas estratégias de leitura variam de acordo com os objetivos da leitura, o grau de letramento dos leitores e as práticas discursivas de que participam.

Dada a complexidade da atividade de leitura, tomá-la como objeto de ensino-aprendizagem não é tarefa simples para o professor. Já há mais de vinte anos,adotando uma perspectiva psicolinguística, Kleiman (1995) postula que a leitura é um processo para o qual converge uma multiplicidade de estratégias cognitivas e que exige o acionamento de vários tipos de conhecimento, como os conhecimentos prévios, os conhecimentos linguístico-textuais e osconhecimentos de mundo, ou enciclopédicos.

Os estudos sobre o ensino da leitura destacam, ainda, a importância de o professor atentar para o fato de que, nas nossas atividades cotidianas, lemos com diferentes propósitos: lemos para nos divertir, deitados em uma rede; para procurar uma palavra no dicionário; para saber se o remédio que vamos tomar pode nos fazer algum mal; para estudar; para ver se o produto que vamos comprar é sal ou açúcar; para nos manter atualizados sobre os acontecimentos do mundo; para saber que o transporte que vamos pegar vai nos levar ao destino pretendido, dentre vários outros objetivos. Os propósitos da leitura também são fatores intervenientes nessa atividade.

Dell'Isola (1991, p.114-115) postula, ainda, que, como atividade escolar, a leitura deve ser trabalhada em três níveis: (1) o da leitura objetiva, no qual o professor conduz os alunos-leitores a perceberem o que está explícito no texto, a exemplo, dentre outros, do estudo do léxico contextualizado; (2) o da leitura inferencial,por meio da qual os leitores 
são levados a perceber o que está implícito no texto, a partir de processos : inferenciais que são elaborados com base em sua visão de mundo, suas experiências e sua bagagem ideológica; e (3) o da leitura avaliativa, na qual o aluno extrapola o texto e manifesta sua postura crítica, a partir de suas ideologias, seus julgamentos pessoais diante das ideias expressadas pelo autor, sua inserção sócio-histórica e cultural etc. Nesse nível de leitura o leitor assume, então, uma atitude responsiva, que lhe vai abrir condições para ser também autor, quando da produção do seu próprio texto-resposta.

Assim como a leitura, a atividade de escrita (na escola e fora dela) tem sido objeto de reflexão de vários estudiosos. De acordo com as concepções atuais, destaca-se a ideia de que um texto se configura como "uma teia de relações, de recursos, de estratégias, de operações, de pressupostos, que promovem a sua construção, que promovem seus modos de sequenciação, que possibilitam seu desenvolvimento temático, sua relevância informativo-contextual, sua coesão e sua coerência, enfim." (ANTUNES, 2009, p.51- 52).

Com o aprofundamento das reflexões sobreo texto e sobre a prática social da escrita, essa prática é hoje percebida e estudada no interior das teorias da enunciação. Enfatiza-se, assim, o fato de que a escrita, sendo "uma atividade interativa, implica uma relação cooperativa entre duas ou mais pessoas" (ANTUNES, 2003, p.44). Exatamente por conta dessa característica, os textos que circulam na sociedade são bastante variados, tanto em sua forma composicional quanto nos gêneros em que se materializam e nas funções que desempenham.

De um ponto de vista socio interativo, a escrita é explicada por Marcuschi (2008, p.77-78), nos seguintes termos: "produzir um texto assemelha-se a jogar um jogo. [...] Para que o jogo ocorra, todos devem colaborar. [...] A produção textual, assim como um jogo coletivo, não é uma atividade unilateral. Envolve decisões conjuntas."

No que se refere especificamente à produção de textos escritos ${ }^{3}$ no contexto escolar, observa-se que uma longa tradição - justificada por uma complexa combinação de fatores históricos, sociais, políticos, culturais, e mantida por forte resistência de alguns setores da nossa sociedade - tem

3 Embora este estudo focalize a produção de textos escritos, a maior parte das afirmações nele feitas é válida, igualmente, para os textos orais. 
amparado a prática de, nas 'aulas de português', privilegiar-se, para os anos iniciais, o desenvolvimento de habilidades motoras e a fixação de regras ortográficas; e, para os anos finais, a apreensão dos conteúdos gramaticais trabalhados, por meio de exercícios nos quais geralmente não se consegue identificar qualquer conexão entre as unidades trabalhadas (geralmente, frases) e uma moldura enunciativa mais ampla.

Apesar dessa prática corrente, não se pode negar que a escrita na/da escola tem sido objeto de constantes e enriquecedoras discussões, as quais têm legado aos interessados pelo tema publicações relevantes sobre questões basilares relacionadas à escrita, abordada nesses estudos do ponto de vista tanto de seus aspectos formais quanto funcionais e textual-discursivos.

Soares (2002, p.171) ressalta "a contribuição das ciências linguísticas ao ensino de português" como "característica fundamental" dessa disciplina, a partir dos anos 1980. Essa contribuição se fez sentir especialmente por meio de reflexões e discussões muito profícuas acerca da heterogeneidade linguística, da riqueza embutida na percepção de língua como um conjunto de variedades, das relações entre língua e sociedade, entre língua e cultura, e dos estudos sobre a dinâmica das interações verbais. As ciências linguísticas avançaram, igualmente, na reflexão sobre o papel da gramática, e foram decisivas para abalar a certeza de que o conhecimento das regras gramaticais seria suficiente para garantir um bom domínio da escrita.

Como resultado de novas discussões e do amadurecimento de ideias, desde os anos 1980 e 1990 assistimos a uma profusão de debates, pesquisas, estudos e publicações sobre o ensino de língua portuguesa em geral, e sobre a escrita na escola em particular. Nesse contexto, ganha força o emprego da expressão "produção de textos", empregada por Geraldi (1997, p.136), em cujo bojo, segundo Bunzen (2006), não está simplesmente a intenção de se fazer uma substituição terminológica, mas, antes, a de operar franca oposição à prática da redação escolar, por avaliar que esta "não leva em consideração as condições de produção das diversas atividades de linguagem que circulam na sociedade (inclusive na própria escola)", configurando-se como uma escrita "para a escola", ou um "mero produto escolar”. ${ }^{4}$ (BUNZEN, 2006, p.148-149)

4 Grifo do autor. 
A prática de produção de textos, então, requer do professor uma : "nova" atitude, norteada por uma concepção (socio)interacional de língua e de texto. Segundo Barros (2012, p.34), quem escreve precisa ter

a compreensão de que todo texto é dialógico, pois todos os enunciados que produzimos são construídos sob a influência do nosso interlocutor e de sua presumida resposta. [...] E se essa é a nossa crença, não nos cabe outro pensamento senão o de que, no ensino da escrita, essa é a primeira coisa a ser explicada e demonstrada para os alunos. Para se transformar em um produtor de textos proficiente, eles precisam estar convictos de que o dialogismo é a essência da atividade linguística.

Assim, no processo de ensino-aprendizagem da produção de textos escritos,professores e aprendizes devem ter a consciência de que as escolhas feitas pelo sujeito-autor decorrem da cena enunciativa, cuja influência se estende, inclusive, para as características formais e a seleção lexical do texto(MARCUSCHI, 2008).A elaboração do texto - que compreende etapas de trabalho distintas - deve acontecer, assim,

em um ambiente em que o aluno se constitua como um autêntico produtor de sentido(s), mediante a execução de uma ação de linguagem. Nessa perspectiva, a escola precisa se tornar um ambiente que favoreça a interação, um ambiente no qual a linguagem preencha a função mediadora entre duas posições enunciativas: a de um sujeito enunciador e a de, pelo menos, um sujeito enunciatário. (BARROS, 2012, p.83)

Sem dúvida, essas noções ampliadas e aprofundadas de leitura e de escrita têm tido forte influência nas práticas docentes escolares. Mas é fato que, no geral, os professores de português entraram, no século XXI, ainda num cenário de muitas incertezas sobre o que ensinar e como ensinar nas aulas de português. Ao lado do consenso de que a escrita e a leitura devem, sim, ser tomadas como objetos de ensino-aprendizagem, no espaço escolar, sendo tarefa do professor de português ajudar o aluno a ser proficiente nessas duas atividades, permanecem muitas dúvidas sobre o papel da 
gramática no processo de ensino-aprendizagem da língua, e sobre a relação que a gramática tem/deve ter com a leitura e a escrita.

\section{Leitura, escrita e 'gramática'}

A ampliação das noções de 'leitura' e de 'escrita' pode levar à conclusão ingênua de que, para trabalhar essas atividades em sala de aula, basta o professor explicitar bem, para os alunos, as condições de produção dos textos a serem lidos/escritos. Pesquisas sobre o tema, entretanto, apontam para outra direção.

Barros (2012), por exemplo, a partir da análise de diversos relatos de alunos, conclui que, no que tange ao ensino da escrita em contextos escolares, "embora a delimitação das condições de produção seja um fator fundamental [...], ela não é suficiente". Na escola, os alunos se ressentem da "falta de um trabalho que [ensine], principalmente, a construir a materialidade linguística do texto" (BARROS, 2012, p.95). Na pesquisa empreendida pela autora, os alunos denunciam a escassez, nas aulas de português, de um trabalho mais específico com os conhecimentos linguísticos (gramaticais), um trabalho que relacione esses conhecimentos com as atividades de leitura e de produção de textos.

Essa escassez pode ser consequência do movimento de oposição (ainda que não declarado) às práticas prescritivo-normativistas, que ainda persistem em muitas escolas do nosso país. Mas é um grande equívoco posicionar-se contra essas práticas pela negação da importância da gramática para a reflexão sobre a língua; ou adotar a posição dos que consideram que a gramática não tem nada a ver com a leitura e a escrita.

Todo texto se produz com base em uma gramática. Aliás, sem gramática não se pode elaborar um texto, uma vez que sua materialidade é essencialmente gramatical. Obviamente, contudo, um texto não se tece apenas de elementos gramaticais, embora eles sejam, para a tessitura do texto, um componente primordial.

No que se refere à leitura, concordamos com Dell'Isola (1991, p.116117), quando ela defende que 
num projeto de leitura, o alicerce está no trabalho com a gramática. Não no sentido que frequentemente tem sido dado nas escolas: a gramática ensinada como um manual de regras e imposições sem mostrar a relação língua/ pensamento. Esse ensino, para a eficiência do trabalho com a leitura, comporta uma outra dimensão: a posição do professor e do aluno como interlocutores. Ler é construir, é perceber o que está, de certa forma, organizado. Essa organização prévia, que nos chega aos olhos e à mente, passa por uma gramática, a base "invisível” da construção. Daí a importância de se estabelecer os alicerces dessa construção.

Ocorre, entretanto, como aponta Dell'Isola,acima, que se mantém no imaginário de muitos professores uma noção restrita de 'gramática' como aquele corpo de normas prescritivas que se encontra nos manuais tradicionalmente usados nas escolas e que é muitas vezes repetido (quase copiado!) em alguns livros didáticos de português. Essa noção restrita de 'gramática', de fato, dialoga pouco com o trabalho escolar de leitura e de produção textual. Pior: as tentativas de diálogo são truncadas, permeadas de mitos sobre restrições e exigências de uma autoridade abstrata, que não se esclarece bem de quem se trata.

Hoje, já é bastante difundida a visão de que o gramático (ou o autor de uma gramática) pode adotar, em relação ao seu objeto de estudo, diferentes posturas ou perspectivas (que não necessariamente se excluem): ele pode ser mais (ou menos) prescritivo - e, coerente com sua perspectiva, apresentarecortes do sistema linguístico como um conjunto de regras que devem ser seguidas por todos os falantes (e escritores), em qualquer circunstância de interlocução(POSSENTI, 2002). Esse conjunto de regras é geralmente referido como "gramática normativa". O gramático também pode ser mais (ou menos) descritivo, quando apresenta recortes do sistema linguístico acompanhados de explicações e comentários sobre como esses recortes são usados pelos falantes (e escritores). $\mathrm{O}$ conjunto de recortes, com as explicações e comentários, é geralmente referido como "gramática descritiva". Na primeira perspectiva, os recortes do sistema são apresentados como 'modelos'; na segunda, como 'possibilidades'. 
Mudando-se o foco do gramático para o usuário de uma língua natural, uma terceira acepção de 'gramática' é aquela que pretende fazer referência ao complexo conjunto de recursos, estratégias, operações, regras que todo falante (de qualquer língua) consegue apreender e sistematizar, pela convivência com (pelo menos) um grupo social. Esse cabedal de conhecimentos é geralmente referido como "gramática internalizada".

É difícil encontrar professores que, na atualidade, discordem da evidência de que ao termo 'gramática' se dão acepções variadas. Mais difícil, porém, é ajudar os professores a descobrirem de que maneira(s) essa evidência pode influenciar, positivamente, suas práticas de sala de aula, quando elesplanejam trabalhar com o tripé 'leitura, escrita e gramática'.

Travaglia (2014) defende que, na sala de aula, as três acepções mais conhecidas de 'gramática' podem conviver pacificamente. Assim, em algumas atividades, o professor pode levar o aluno a "despertar" para aspectos que fazem parte da sua 'gramática internalizada', que, nas palavras do autor, é o "conhecimento linguístico não explícito que temos"; em outras, o professor pode trabalhar com questões que dizem respeito ao "mecanismo da língua", a "como a língua é constituída e como funciona";por fim, em outras atividades, o professor pode trazer à luz algumas "regras sociais de uso da língua e suas variedades".

Consideramos, entretanto, que, na prática pedagógica, essa “convivência pacífica” entre as três acepções de 'gramática', defendida por Travaglia (2014), é praticamente impossível de concretizar-se. Isso porque, obviamente, uma "gramática normativa" difere de uma "gramática descritiva" muito mais do que simplesmente por conta dos diferentes tratamentos que seus autores conferem às questões linguísticas. De fato, a maneira particular de tratar essas questões já reflete diferentes concepções de língua/linguagem e de ciência, aponta para diferentes objetivos e reflete diferentes inserções sócio-históricas.

Por outro lado, parece-nos muito profícua a orientação de Geraldi (1997), para quem as aulas de português deveriam mesclar três tipos de atividades:atividades linguísticas (de usos da língua), epilinguísticas (de reflexão sobre os fatos linguísticos) e metalinguísticas (que capacitam o aprendiz a falar/escrever sobre a própria linguagem, utilizando para isso, inclusive, a terminologia especializada dessa área de conhecimento). É 
importante ressaltar que, ao lado dessa orientação geral, o autor defende : "a produção de textos (orais e escritos) como ponto de partida (e ponto de chegada) de todo o processo de ensino/aprendizagem da língua", isso porque "é [...] no texto que a língua - objeto de estudo - se revela em sua totalidade" (1997, p.135).

Assim, ao explicitar o que considera as "unidades básicas do ensino de português”, Geraldi (2002, p.59-79) menciona: “a prática de leitura de textos, a prática de produção de textos e a prática de análise linguística”. Sobre esta última, que nos interessa mais de perto, o autor esclarece que ela "inclui tanto o trabalho sobre questões tradicionais da gramática quanto questões amplas a propósito do texto", e deve sempre "partir dos problemas encontrados nos textos escritos pelos alunos". Uma aula de análise linguística consistiria fundamentalmente na "retomada do texto do aluno", que, após refletir sobre alguma questão de natureza gramatical ou textual, teria a oportunidade de reescrever seu texto, alterando o que avaliasse como problemático.

$\mathrm{Na}$ esteira de Geraldi (2002),ressaltamos que 'leitura', 'produção de textos' e 'análise linguística' devem ser tomadas como atividades integradas, por meio das quais os aprendizes constroem e ampliam seu conhecimento linguístico, com a ajuda do professor, num movimento contínuo de lerescrever-analisar-reler-reescrever.

Desse modo, na sala de aula, o professor tem um importante papel no sentido de ampliar as oportunidades para que os alunos sejam capazes de perceber, analisar e manipular os arranjos gramaticais do seu sistema linguístico - sistema que já dominam bem -, de tal maneira que consigam tanto atribuir sentidos aos textos que leem quanto expressar os sentidos que pretendem expressar, quando assumem o papel de sujeito-autor, percebendo a diversidade e a eficácia dos diversos recursos gramaticais selecionados, quando da leitura ou da escrita de um texto.

Insistimos: ao assumir-se como locutor, na escrita, ou como interlocutor, na leitura, o aprendiz opera obrigatoriamente com a bagagem de conhecimentos gramaticais que vem construindo ao longo de sua vida. Nessa convergência obrigatória entre leitura, escrita e gramática, cabe ao professor acompanhar e guiar o aluno em seu processo de vivência da linguagem, processo no qual as operações que ele realiza devem ir ficando 
cada vez mais conscientes, até o estágio em que ele consiga relacionar suas escolhas gramaticais com a cena enunciativa na qual se envolve, sempre : que lê ou escreve.

\section{CONSIDERAÇÕES FINAIS}

Pretendemos corroborar, com este trabalho, a visão de que ler e escrever são atividades que exigem o acionamento de uma multiplicidade de habilidades e competências, tanto cognitivas quanto textuais e interacionais,as quais concorrem conjuntamente para que certo(s) propósito(s) seja(m) alcançado(s). Na complexidade com que a leitura e a escrita se processam, a ativação de um saber gramatical se destaca como condição sinequa non para que elas ocorram.

No contexto escolar, em que a leitura e a escrita são tomadas como objetos de ensino-aprendizagem, o estudo do componente gramatical deve contribuir para "abrir caminhos", no sentido de propiciar aos estudantes uma visão ampliada das possibilidades de seu sistema linguístico. Concordamos com Bagno (2002, p.197), quando ele afirma que "a função primordial do ensino de língua na escola [...] [é] favorecer a criação de condições para o letramento contínuo e ininterrupto dos alunos, isto é, para a aquisição e pleno desenvolvimento das habilidades de leitura e de escrita, associadas a práticas relevantes de oralidade e à reflexão sobre a língua.”

Certamente nos acostumamos a ouvir e a repetir que "ler e escrever se aprendem lendo e escrevendo". Dita dessa maneira, essa afirmação traduz apenas uma meia-verdade. O que, de fato, acontece é que nossos alunos aprendem a ler e a escrever quando possibilitamos que eles vivenciem práticas significativas, por meio das quais eles experimentam "o caráter dialógico da linguagem"(LEAL, 2003, p.65-66).

Soares (2006, p.39) distingue entre“aprender" a ler e escrever” e "apropriar-se da leitura e da escrita”. Para ela, aprender a ler e escrever corresponde "a adquirir uma tecnologia, a de codificar em língua escrita e de decodificar a língua escrita”, enquanto apropriar-se da leitura e da escrita"é tornar a escrita e a leitura'próprias', ou seja, é assumi-las como sua 'propriedade'. Deixamos registrada, nessas linhas conclusivas, nossa expectativa de que o estudo da gramática, nas aulas de português, abra caminhos para que essa apropriação realmente se efetive. 


\section{REFERÊNCIAS BIBLIOGRÁFICAS}

: ANTUNES, I. Aula de português: encontro e interação. São Paulo: Parábola, 2003.

ANTUNES, I. Língua, texto e ensino. Outra escola possível. São Paulo: Parábola, 2009.

BAGNO, M. Língua, história e sociedade: breve retrospecto da normapadrão brasileira. In: BAGNO, M. (Org.). Linguística da norma. São Paulo: Edições Loyola, 2002, p.179-199.

BARROS, L. F. P. O professor e a produção de textos escritos: O que se ensina quando se ensina a escrever? Por que se ensina o que se ensina? Tese (Doutorado em Letras). Programa de Pós-Graduação em Estudos Linguísticos, Universidade Federal de Minas Gerais, Belo Horizonte, 2012.

BUNZEN, C. Da era da composição à era dos gêneros: o ensino de produção de texto no ensino médio. In: BUNZEN, C. e MENDONÇA, M. (Orgs.). Português no ensino médio e formação do professor. São Paulo: Parábola, 2006, p.139-161.

DELL'ISOLA, R.L.P. Leitura: inferências e contexto sociocultural. Belo Horizonte: Universitária, 1991.

GERALDI, J. W. Portos de passagem. 4º ed. São Paulo: Martins Fontes, 1997.

GERALDI, J. W. Unidades básicas do ensino de português. In: GERALDI, J. W. (Org.). O texto na sala de aula. São Paulo: Ática, 2002, p.59-79.

GOMES, Maria Lúcia Moreira. Da materialidade do texto à constituição do leitor. A prática interacionista da leitura como ponto de partida para a instigação sociocognitiva. In: Vértices, ano $5, \mathrm{n}^{\mathrm{a}}$ 3, Campos dos Goytacazes, RJ, set/dez 2003.

KLEIMAN, A. Texto e leitor. Aspectos cognitivos da leitura. 4ำ ed. São Paulo: Pontes, 1995.

LEAL, L. F. V. A formação do produtor de texto escrito na escola: uma análise das relações entre os processos interlocutivos e os processos de 
ensino. In: COSTA VAL, M. G. e ROCHA, G. Reflexões sobre práticas escolares de produção de texto: o sujeito-autor. Belo Horizonte: Autêntica, : 2003, p.53-67.

MARCUSCHI, L. A. Produção textual, análise de gêneros e compreensão. São Paulo: Parábola, 2008.

POSSENTI, S. Gramática e política. In: GERALDI, J. W. (Org.). O texto na sala de aula. São Paulo: Ática, 2002, p.47-56.

RIBEIRO, Ormezinda Maria. Por uma engenharia da leitura. Construindo trajetórias para a leiturização. In: Linguagem \& Ensino, vol. 6, n 2, Pelotas, jul/dez 2003, p.107-148.

RODRIGUES, Nara Caetano. Leitura nos ensinos fundamental e médio: reflexões sobre algumas práticas. In: Linguagem em (Dis)curso - LemD, v. 7, $\mathrm{n}^{\circ}$ 2, Tubarão, mai/ago 2007, p.215-240.

SANTOS, Carmi Ferraz. O ensino da leitura e a formação em serviço do professor. In: Teias,ano 3, n⿳亠丷厂 5, Rio de Janeiro, jan/jun 2002.

SILVA, A. C. Modos de (re)configuração da gramática textual: desenvolvimento de competências de leitura e escrita. s/d. Disponível em:https://repositorium.sdum.uminho.pt/bitstream/1822/14936/3/ Modos $\% 20$ de $\% 20$ (re)configura $\%$ C3\%A 7\%C3\%A3o $\% 20$ da $\% 20$ gram\%C3\%A1tica\%20textual.pdf. Acessado em 29/11/2015.

SOARES, M. Português na escola. História de uma disciplina curricular. In: BAGNO, M. (Org.). Linguística da norma. São Paulo: Ed. Loyola, 2002.

SOARES, Magda. Letramento: um tema em três gêneros. $2^{\circ}$ ed. Belo Horizonte: Autêntica, 2006.

SOARES, Magda. Alfabetização e letramento. São Paulo: Contexto, 2003.

TRAVAGLIA, L. C. Na trilha da gramática: conhecimento linguístico na alfabetização e letramento. 2014. Disponível emwww.books.google.com. Acesso em 20/11/2015. 